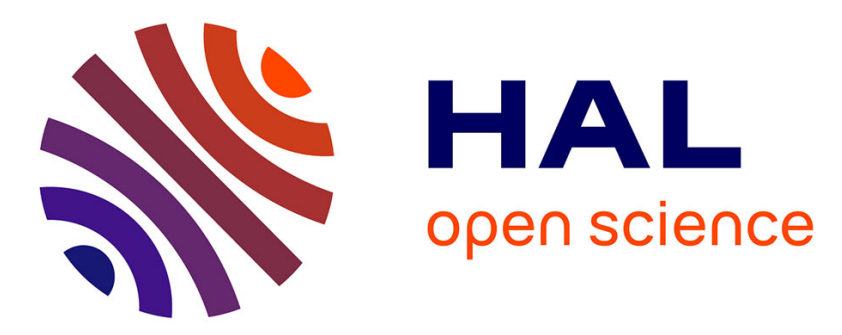

\title{
The Methodological Challenges Related to Assess the Outcomes of Knowledge Management Initiatives: The Case of Communities of Practice
}

Patrick Mbassegue, Mickaël Gardoni

\section{- To cite this version:}

Patrick Mbassegue, Mickaël Gardoni. The Methodological Challenges Related to Assess the Outcomes of Knowledge Management Initiatives: The Case of Communities of Practice. 15th IFIP International Conference on Product Lifecycle Management (PLM), Jul 2018, Turin, Italy. pp.579-589, 10.1007/978-3-030-01614-2_53. hal-02075565

\author{
HAL Id: hal-02075565 \\ https://hal.inria.fr/hal-02075565
}

Submitted on 21 Mar 2019

HAL is a multi-disciplinary open access archive for the deposit and dissemination of scientific research documents, whether they are published or not. The documents may come from teaching and research institutions in France or abroad, or from public or private research centers.
L'archive ouverte pluridisciplinaire HAL, est destinée au dépôt et à la diffusion de documents scientifiques de niveau recherche, publiés ou non, émanant des établissements d'enseignement et de recherche français ou étrangers, des laboratoires publics ou privés.

\section{(c)(1)}

Distributed under a Creative Commons Attribution| 4.0 International License 


\title{
The methodological challenges related to assess the outcomes of knowledge management initiatives: the case of communities of practice \\ Patrick Mbassegue ${ }^{1}$, Mickaël Gardoni ${ }^{2}$
}

\author{
${ }^{1}$ Ecole Polytechnique, 2900 Bd Edouard Montpetit, H3T1J4, Montreal, Canada \\ ${ }^{2}$ Ecole de Technologie Supérieure, 1100 Notre-Dame, H3C1K3, Montreal, Canada \\ patrick.mbassegue@polymtl.ca/ mickael.gardonidetsmtl.ca
}

\begin{abstract}
In any organizational project where the use of limited resources represents a challenge, it's necessary to assess the outcomes generated. The methodological approach on how to assess outcomes reveals many questions, namely: What is the best way to do so? What dimensions to assess? From what criteria? How to estimate them? In the case of communities of practice (CoP), these questions become accurate. Indeed, in the case of Communities of Practice, the participants represent the cornerstone of the project because there are the ones who generate knowledge. So to assess outcomes generated by CoP within an organization, it's necessary to identify an adapted methodological frame which will allow to take into account the critical aspects of the $\mathrm{CoP}$ and the user perspective. Our proposal aims to present a hybrid path (qualitativequantitative) in order to minimize the limits and uplift advantages related to both approaches. The addition of these two approaches must generate a more stronger one and a better reliability of concept. For that purpose, the structure of the article concerns the following aspects: the context of knowledge management initiatives and particularly communities of practice; notions of assessment and outcomes; the current methodologies used to assess the outcomes of the $\mathrm{CoP}$ as well as their limits; the criteria to be respected for the choice as a strong methodology; the choice of a new approach (qualitative-quantitative) and its future application in the CoP.
\end{abstract}

Keywords: communities of practice, mixed methodology, assessment.

\section{The context of knowledge management (KM), communities of practice (CoP) and product lifecycle management (PLM)}

\subsection{The link between knowledge management (KM) and PLM}

PLM and KM are two frameworks that are improving organizational performance. PLM is about managing and optimizing every step of product development across the entire lifecycle. In this sense, PLM can generate effective solutions that contribute to value creation. In addition, all these activities and solutions are based on knowledge management. For example, knowing how to manage knowledge make PLM enabled 
activities and solutions efficient. So, by establishing KM practices that promote organizational performance, PLM activities are also being improved.

Several authors establish the need to associate PLM and KM [1], [2], [3]. For McMahon et al. [4], KM is an enabler of PLM and vice versa because the activities of codification, dissemination, sharing, re-use and creation of knowledge underlie all PLM activities. As well as the lessons learned from PLM activities enrich the stock of knowledge available in the organization [5]. On this basis, we believe that KM and PLM are efficient by integrating the activities of the two frameworks (Figure 1).

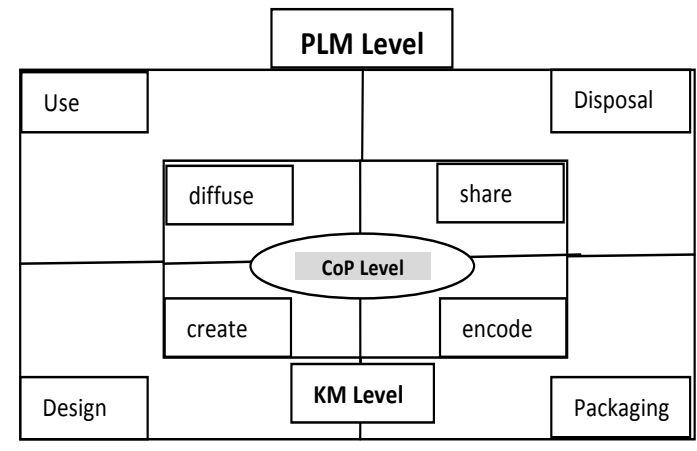

Fig. 1. Illustration of the KM-PLM integration

Incidentally, to establish how to capitalize on this integrated framework, the CoP is one of the knowledge management initiatives that can support continuous PLM improvement. But for that, it is necessary to identify the challenges and issues related to the benefits that can be generated by CoPs. But to do this many methodological challenges arise.

\subsection{Knowledge management (KM) and communities of practice (CoP): benefits and perspective}

Knowledge management refers to activities of production, dissemination, sharing and acquisition of knowledge. In a context where organizations (public, private, community, professional) are submitted to deliver better performance, knowledge management activities lead to better results [6], [7]. In the same way as new technologies (equipment) or intangible resources (patents, software, applications), knowledge management improves organizational efficiency by improving productivity and processes that contribute to produce better services with quality, speed and effective decrease in the consumption of resources [8]. Knowledge management concerns different types of projects, namely COP, interactive data base, best practices [9].

$\mathrm{CoP}$ is viewed as a group where participants and experts share their knowledge on an ongoing basis. For Zboralski \& al. [10], CoP represent a group of people who interact with each other in, both inside and outside of the organization. They are both sharing the same interest. CoP is one of the most effective project in knowledge man- 
agement initiatives [11]. It is a framework in which employees as participants are both beneficiaries and producers of knowledge. Different mechanisms and conditions are at stake to ensure the implementation of the CoPs [10], [12]. But the essential element remains the participant. CoP requires different types of resources (human, financial, logistics, informational), so it's important for any given organizations to answer the crucial question of return on investment, namely benefits and impacts generated [13], [14]. To answer to the concern of those who carry out this type of initiative in different organizational contexts (large or medium-sized enterprises, manufacturing companies, research centers, professional groups, etc.), great attention must be paid to evaluate the benefits. The benefits can be viewed as impacts for the participants of a CoP, because they are the one who generated value added. For Mitchell \& al. [15] these benefits are on three levels, namely individuals, organizational practice and productivity (Table 1).

Table 1: Benefits of Communities of Practice [15]

\begin{tabular}{|c|c|c|}
\hline $\begin{array}{c}\text { Benefits on organizational } \\
\text { practice }\end{array}$ & $\begin{array}{l}\text { Benefits on organisa- } \\
\text { tional productivity }\end{array}$ & $\begin{array}{l}\text { Benefits for indi- } \\
\text { viduals }\end{array}$ \\
\hline $\begin{array}{l}\text { 1- Generate knowledge and } \\
\text { encurage skills development } \\
\text { 2- Use knowledge manage- } \\
\text { ment to drive strategy } \\
\text { 3- Disseminate valuable in- } \\
\text { formation and transfer best } \\
\text { practice } \\
\text { 4- Iniate new lines of busi- } \\
\text { ness including new products } \\
\text { and services }\end{array}$ & $\begin{array}{l}\text { 1- Facilitate rapid re- } \\
\text { sponses to customer needs } \\
\text { and problems } \\
\text { 2- Decrease the learning } \\
\text { curve for new employees } \\
\text { 3- Help companies re- } \\
\text { cruit and certain talent }\end{array}$ & $\begin{array}{l}\text { 1- Enable employ- } \\
\text { ees to manage change } \\
2 \text { - Provide access to } \\
\text { new knowledge } \\
3 \text { - Forster trust and } \\
\text { a sense of common } \\
\text { purpose } \\
4-\text { Add value to } \\
\text { professional lives }\end{array}$ \\
\hline
\end{tabular}

\subsection{The need to evaluate the benefits of a CoP through impacts assessment}

Impacts correspond to the changes of a state in a given situation. Two different moments are identified, namely before and after the implementation of the CoP. The gap between these two situations symbolizes the impact. An impact is a specific outcome that is linked to what has been implemented. The impact can therefore be of different types, including social, cultural, financial, technological, behavioral, learning, etc. Moreover, it can be identified at different levels: personal, collective, organizational, administrative, operational, departmental. In addition, as the core of the CoP is the participants and they play a critical role, the impacts to be determined are those that the participants experienced.

To identify such impacts, emphasis should be placed on the assessment function which is different from the one of the measure. Assessment consists of a systematic collection and analysis of information of a phenomenon or system. With an assessment method, it's possible to establish logical links of cause and effect and to determine the changes and modifications obtained by employees involved in a CoP. In this sense assessment allows a construction of meaning of a transformation dynamic to 
reach different goals. It's also a basis to identify outcome, to ensure the relevance of the organizational response. It's about providing information to understand progress and the degree of success. In this sense, assessment is a process that concerns different components [15], [10].

Thus, different types of assessment are available, namely: formative, summative, process and results. All these forms are for specific purpose. Nevertheless, they can all be realized on the same organizational system thus allow to have a richer understanding of the system to be evaluated. The choice of the type of assessment is made according to various criteria among others: the objectives, the priorities, the goals, the ways in which the results will be used. The nature of questions also differs according to the type of assessment. Finally, in terms of method, there are mainly 3 main stages: (1) stage $1=$ before (at the beginning of the process); (2) stage $2=$ during the process; (3) stage $3=$ after (at the end of the process). These 3 -step can be accompanied by a quasi-experimental approach with a control group or without one. In both ways, it's important to compare the two periods, namely before and after. With the presence of a control group, one can distinguish between an exposed and an unexposed reference group, so one can ensure that the result obtained is directly related to the actions and practices implemented. On the other hand, mobilizing a control group is often difficult to apply and expensive.

In addition, there are two types of methods, qualitative and quantitative research [16], [17], [18], [19]. With qualitative evaluation the emphasis is on non-numerical data. The focus is to understand a phenomenon. Thus, the focus is on why, and how the event materializes. It allows first to establish the presence of an impact and in the second time to give a rich picture. It is difficult to use a large sample since the emphasis is on better explanation (richness of explanation). There is therefore a limit to the generalization of the results. The qualitative approach helps to understand behaviors. The analysis based there is to compare. The quantitative evaluation is based on numerical data. Thus, the focus is on the what questions. The need of statistical indicators is necessary to establish links and to give robustness to result. The generalization can be made. Consequently, to assess impacts of communities of practice raises many questions that will be discussed in the following paragraph and based on literature review. It is therefore necessary to establish the methodological bases to be able to determine the impacts in a robust way, by assuming validity, and reliability of the components of the evaluation model. For this, it is important to identify the methodological frameworks found in the literature on CoP assessment.

\section{Review of literature for methodological approach to assess CoP}

\subsection{What dimensions are at stake to assess CoP\$? A problematic review}

The assessment function is a proven approach in many descriptions to establish the impacts, particularly in education, management, engineering [10]. But one of the issues lies in the methodology to be retained. It appears that the situation of the CoP is specific for a variety of reasons, including: knowledge belongs to individuals, evaluation is a process, impacts are assumed to evolve over time. It is therefore important to 
integrate the temporal dimension, the diversity of the forms of evaluation induces to identify the appropriate methodology [20], [21]. For the moment, valuation models focus on financial, operational, functional or strategic impacts: these represent structural dimensions of the organization. However, the point of view of the usersparticipants is essential, because in the initiatives of the communities of practice, their role is critical since they are the ones who possess the knowledge [22], [23], [24]. Therefore, the viability of the CoP rests with them, and also the results pursued by the organization implementing this type of project.

Given these observations, this proposal aims to develop an impact assessment framework from the point of view of the participants by using an approach based on the transformation of inputs into outputs. However, knowledge management, and particularly CoPs require the development of a dedicated assessment framework that favors the perspective of users or participants. In addition, since it is recognized that assessment is a process, impacts are assumed to evolve over time [14]. It is therefore important to integrate the temporal dimension, the diversity of the forms of assessment induces to identify the appropriate methodology. Indeed, the approach advocated to establish the impacts is linked to the robustness of the results, especially in the case of the COPs, because it represents an organizational system filled with humans. Therefore, interactions established by the participants contribute to the formalization of the impacts. Should we favor a qualitative or quantitative approach? Should the profile of the participants be taken into account? Should the duration of participation or the clear statement of objectives be taken into account beforehand?

\subsection{Dimensions related to methodological approach}

From the literature, it has been possible to establish the limits and advantages of current methodological frameworks that have been used in the case of various studies and research on communities of practice. To highlight what is known about the methodological approaches used in the literature review, six specific dimensions were selected. These six dimensions make it possible to adequately describe a methodological approach. We distinguish for this purpose: (1) The inductive or deductive approach; (2) The type of context chosen (specific or generic); (3) The method of data collection; (4) The unit of analysis; (5) The existence of a theoretical model a priori; (6) The type of research. These six dimensions are summarized in table 2 . The analysis of the various parameters makes it possible to identify a certain number of advantages and limits. Benefits are new ways of doing things. Thus, among the aspects that seem important, let us underline, among others: (1) the type of research; (2) the theoretical framework; (3) methods of data collection.

Indeed, the distinction of the type of research makes it possible to be able to carry out a variety of research: this allows to enrich the understanding that one can have of this object of study. And therefore a richer understanding, ("rich picture") will also help develop more robust intervention tools. Being able to carry out as much qualitative as quantitative studies brings a lot of latitude in the design of the research. In addition, identifying the research contexts, specifying the sectors, the types of organization, appears also important, insofar as specifically in the field of knowledge management, the contextual dimensions are critical. Finally, the identification of the vari- 
ous means of data collection related to the methodological frameworks analyzed shows that it is necessary to rely on a variety of instruments to obtain specific data. And it is from these diverse data that we can produce fine and rich analyzes. In short, these three dimensions noted in relation to the methodologies analyzed deserve to be taken into account in the development of our research design.

Table 2: Dimensions related to methodological process to assess CoP

\begin{tabular}{|c|c|}
\hline Dimensions & Result and references \\
\hline \multirow{2}{*}{$\begin{array}{l}\text { Inductive or } \\
\text { Deductive } \\
\text { Approach }\end{array}$} & Inductive $=20 \%$ of cases studies [16], [25]. \\
\hline & Deductive $=80 \%$ of cases studies [26], [27]. \\
\hline \multirow[t]{2}{*}{ Context } & Organization specified $=30 \%$ of cases studies [22], [25]. \\
\hline & Sector specified $=60 \%$ of cases studies [23], [28]. \\
\hline \multirow{4}{*}{$\begin{array}{l}\text { Method of data } \\
\text { collection }\end{array}$} & Questionnaire specified $=50 \%$ of cases studies [7], [25]. \\
\hline & Interview specified $=40 \%$ of case studies [28], [25]. \\
\hline & Internal documentations specified $=40 \%$ of cases studies [15], [29]. \\
\hline & Observations in situ specified $=30 \%$ of case studies [16], [28]. \\
\hline \multirow[t]{3}{*}{ Unit of analysis } & Individual level $=5 \%$ of case studies [25]. \\
\hline & Group level $=35 \%$ of case studies [28]. \\
\hline & Organizational level $=75 \%$ of case studies [26], [30]. \\
\hline \multirow{2}{*}{$\begin{array}{l}\text { Identification of a } \\
\text { theorical model }\end{array}$} & Identified $=80 \%$ of case studies [22]. \\
\hline & Not Identified $=20 \%$ of case studies [16]. \\
\hline \multirow[t]{2}{*}{ Type of research } & Qualitative $=50 \%$ of case studies [16]. \\
\hline & Quantitative $=50 \%$ of case studies [31], [29]. \\
\hline
\end{tabular}

Nevertheless, a number of limitations deserve to be emphasized. First, the emphasis is on the level of analysis. Preponderance is at the organizational level. The individual level seems less taken into account, but knowledge belongs to individuals. This would be a gap to be filled. Second, the methodologies analyzed do not capture all the organizational ramifications that are specific in a community of practice. These ramifications ensure that many organizational aspects are inevitably affected and transformed, including: input-output processes, technologies, human resources, production volumes, performance, interaction dynamics, productivity and management of team's work. Given that many authors [31], [26] emphasize and recognize that knowledge management projects target and touch different aspects of the organization, it would 
therefore be appropriate to link these different affected aspects as inputs, outputs and processes. The analysis of the limitations that affect the methodological frameworks used in research related to communities of practice assessment shows that there are various critical aspects that are not taken into account. Therefore, in the context of this work, it is necessary to propose methodological avenues that will make it possible to fill these gaps.

\section{Result for a proposal of a new approach to assess CoP}

\subsection{Basis and presentation of a new methodological approach}

Based on literature review, qualitative and quantitative assessments are present. Qualitative assessments rely on induction and rich descriptions that take into account the individual experience [20], [32]. It is undeniable that given the contextual dynamics of a $\mathrm{CoP}$ characterized by a system of collective action and interactions between the participants, all this leads to the recognition of a certain complexity. This complexity requires an interest in the changes that users experienced, the behaviors and the knowledge they acquired. Identifying and understanding the changes that are taking place among CoP participants is needed. Not only will we be able to identify the impacts, but also explain the reasons behind them. Thus, to arrive at the description of the point of view of the users-participants in the CoP, a qualitative approach is to be considered [20].

This dual qualitative-quantitative position leads us to consider a hybrid methodological approach [32], [19]. This position is relevant given the specification of the evaluation function and the specific context of the CoPs. In addition, the classification of qualitative studies on one side and quantitative studies on the other do not conventionally permit the combination of the two approaches. However, the hybrid approach that we propose is a viable methodology. The hybrid approach therefore makes it possible to combine qualitative and quantitative data. Thus, the hybrid methodological framework elaborated is divided into 4 stages:

1. Stage $1=$ identification of critical variables from the literature review

2. Stage $2=$ testing of critical variables with users. This action aims to better un derstand and characterize the object of research. This anchoring is necessary in view of the complexity and peculiarities of any evaluation process and the knowledge management dynamics within a CoP.

3. Stage $3=$ validation of the built model: this requires checking the validity of construct or conceptual and internal validity and reliability. Reliability refers to the degree of accuracy with which an instrument measures the concept, in this case the benefits of a CoP. Construct or conceptual validity ensures that the instrument, in this case the conceptual model is well constructed and that it offers an adequate measure of the theoretical model mobilized. The occurrence of input-output model can also be associated with the validity of content that aims to determine whether the measuring instrument and its components represent the concept. 
4. Stage $4=$ the application of the model in specific organizational situations. The case study is the preferred approach in this phase. Since the focus is on impacts, a more qualitative approach is preferred. Indeed, the case study makes it possi ble to clearly define the situation and the context to analyze. We can therefore have a rich understanding of how participants get their benefits.

The hybrid method approach established a structured CoP evaluation model with six components: income, inputs, throughput, output, outcomes, maturity and auditing initial conditions. This systemic model makes it possible to establish a logical link between the various components. Thus, it is possible from the perspective of users to determine the outcomes and impacts they have achieved based on their participation in the COP.

\subsection{Results and benefits of the mixed methodology}

This methodological approach is necessary to meet the dual objective of the study, mainly the validation of the model on the one hand and the identification of impacts due to participation in a CoP. This reduces the weaknesses inherent in each of the initial approaches (qualitative and quantitative). There are several advantages inherent to the strength of the hybrid approach: complementarity, explanation and exploration [32],[19]. Complementarity allows for analysis at different levels regarding the impact of CoPs on participants. The qualitative approach enriches this understanding by focusing on users' experiences. The explanation is richer because the qualitative data provide deeper insights. The observation of the presence of phenomena is not only established by a quantitative basis, but it is also explained by aspects and strategies of appropriation. Exploration is necessary because the benefits and impacts are based primarily on ownership and changing individual practices. Exploration allows to discover the variety of individual situations that illustrates the materialization of the fallout.

In the proposal of an evaluation model, two important criteria for ensuring its robustness and relevance are reliability and fidelity. Both criteria require a statistically significant sample that favors a quantitative approach. The use of statistical tests is necessary. Adherence to the acceptance or rejection criteria is the main criterion, notably by calculating, Cronbach's alpha, coefficient of variation, KMO factor, kurtosis and skewness factors and so on. The quantitative approach thus favored makes it possible to base the model built on a statistically reliable basis since the respondents to the validation questionnaire are in agreement with their knowledge, their interests, their expectations, their practices, in short what they are looking for in an impact assessment model. In addition, a specific important advantage of the hybrid or mixed method is also the process of data collection and processing [32], [19]. Thus, it is to begin first with a quantitative study (testing or conceptualization or theoretical validation) followed by a qualitative study (exploration of cases). It is also possible to start with a qualitative study to discover the parameters constituting the phenomenon under study and then continue with a quantitative study for recurrences and generalization from a random sample that meets the rules of statistical generalization. The proposed hybrid approach identifies different methodological benefits, including: a)- The use of numeric and non-numerical data; b)- The diversity of data; c)-The triangulation of 
data. The use of statistical tests to validate the model ensures that the components retained in the conceptual model are relevant and can be applied in different contexts.

Finally, the specific situation of the $\mathrm{CoP}$ requires consideration of the concepts of change and stakeholder; which is needed, because in a CoP, the participants play a critical role. Therefore it's important to compare the situation of participants before they participate in knowledge sharing activities and after doing so. This type of evaluation also requires taking into account the time frame: this is easily achievable with a case study. The proposed hybrid methodological approach thus brings benefits both at the conceptual level (model development framework) and empirically (validation and field testing). Which ultimately results in informative, robust and pragmatic results.

\section{Conclusion and future work}

The application of the methodological approach is the next step, that of collecting data to obtain factual results. One of the stakes in this strategy of research refers to the type of sample to be compiled both for the quantitative and the qualitative part.

For the quantitative approach, a survey will be conducted among participants in communities of practice regardless of their organizational context. The aim is for them to express themselves on the conceptual model from their experience, practices, expectations and targets they seek by participating in a CoP. From their answers, we will be able to validate the conceptual model.

For the qualitative part, the sample to be selected corresponds to a convenience sample in so far as the east and the data collection are in a specific organization. These are accessibility and practical reasons that will make it possible to identify the case studies in which the conceptual model will have to be tested.

The idea is to extend the application of the conceptual model to different cases in different contexts and by different types of users taking into account also different levels of maturity. This multiplication of application will make it possible to arrive at the theoretical saturation necessary, thus, allowing to reach a double validation as much on the conceptual level as practical. The next steps are aimed at achieving these results.

\section{References}

1. Folkard, B., Keraron, Y., Mantoulan, D., Dubois, R.: The Need for Improved Integration Between PLM and Knowledge Management: A PLM Services Provider Point of View in Rivest, L. \& Bouras, A. (eds.). Towards Knowledge-Rich Enterprises. 9th International Conference on PLM, July 2012, 85-98. doi:10.1007/978-3-642-35758-98

2. Bernell-Garcia, P., Fan, I.-S.: Practitioner Requirements for Integrated Knowledged Based Engineering in PLM. International Journal of Product Lifecycle Management, 3, 1, 3-20 (2008). doi:10.1504/IJPLM.2008.019968

3. Beylier, C., Pourroy, F., Villeneuve, F., Mille, A.: A Collaboration Centered Approach to Manage Engineering Knowledge; A Case Study of An Engineering SME. Journal of Engineering Design, 20, 6, 523-542 (2003). doi:10.1080/09544820801898482 
4. McMahon, C., Lowe, A., Culley, S.: Knowledge Management in Engineering Design: Personalization and Codification. Journal of Engineering Design, 15, 4, 307-325 (2003). doi:10.1080/09544820410001697154

5. Trotta, M. G.: PLM: Sustainability and Knowledge Management As Keys in A Complex System of Product Development. Journal of Industrial Engineering and Management, 3, 2, 309-322 (2010). doi:10.3926/jiem.2010

6. Carrillo, J. E., Gaimon, C.: Improving Manufacturing Performance Through Process Change and Knowledge Creation. Management Science, February, 265-288 (2000). doi: 10.1287/mnsc.46.2.265.925

7. Marqués, D.P., Simon, F.J.G.: The Effect of Knowledge Management Practices on Firm Performance. Journal of Knowledge Management, 10, 3, 143-156 (2006). doi10.1108/13673270610670911

8. Lesser, E. L., Storck, J.: Communities Of Practice And Organizational Performance, IBM System Journal, 40, 831-841 (2001).

9. Siddique, C.M.: Knowledge Management Initiatives in the United Arab Emirates: A Baseline Study. Journal of Knowledge Management, 16, 5, $702-723$ (2012). doi:10.1108/13673271211262763

10. Zboralski, K., Gemunden, G., H.: Encyclopedia of Communities of Practice in Information and Knowledge Management. IDEA GROUP Reference, London (2006). doi:10.1108/09504120710775246

11. Heisig, P.: Harmonisation of Knowledge Management. Comparing 160 Knowledge Management Frameworks around the Globe. Journal of Knowledge Management, 13, 4, 431 (2009). doi:10.1108/13673270910971798

12. Wenger, E., McDermott, R., Snyder, Y. M.: Cultivating Communities of Practice : A Guide to Managing Knowledge. Harvard Business School Press, Boston (2002).

13. Fontaine, M, A. \& Millen, D., R.: Understanding the Value of Communities: A Look o Both Sides of The Cost/Benefit Equation. Knowledge Management Review, 5, 3, 24-27 (2002). doi:10.11/1985500

14. Chetty, L. \& Mearns, M.: Using Communities of Practice Towards The Next Level of Knowledge Management Maturity. SA Journal of Information Management, 14, 1, 503509 (2002). doi:10.4102/sajim.v14i.503

15. Mitchell, J. \& Wood, S.: Benefits of Communities of Practice. John Mitchell \& Associates, Toronto.retrieved from www.jma.com.au/pages/communities-of-practice/c-ofp-benefits.pdf? (2001).

16. Harlow, H.: The Effect of Tacit Knowledge On Firm Performance. Journal of Knowledge Management, 12, 1, 148-163 (2008). doi:10.1108/13673270810852458

17. Zaim, H., Tatoglu, E. et Zaim, S.: Performance of Knowledge Management Practices: A Causal Analysis. Journal of Knowledge Management, 11, 6, 54-67 (2007). doi:10.1108/13673270710832163

18. Pillania, R. K.: Information Technology Strategy For Knowledge Management In India Automotive Components SMEs. Knowledge and Process Management, July/September, 15, 3, 203-210 (2008). doi:10.1002/kpm.311

19. Teddie, C., Tashakkori, A.: Foundations of Mixed Methods Research. Integrating Quantitative Approaches in The Social and Behavioral Sciences. Sage, Thousand Oaks, CA (2009).

20. Creswell, J., W.: Research Design: Qualitative and Quantitative Approaches. Thousand Oaks, CA. (1994)

21. Molina-Azorin, J.: The Use and Added Value of Mixed Methods in Management Research. Electronic Journal of Mixed Methods Research, 5, 1, 7-24 (2010). doi10.1177/1558689810384490

22. Verburg, R. M., Andriessen, J. H. E.: The Assessment Of Communities Of Practice. Knowledge and Process Management, 13, 1, 13-25 (2006). doi:10.1002/kpm.241 
23. Yanklin, S., Igel, B.: Communities Of Practice Purposefully Designed For Improving Business Performance. Knowledge and Process Management, 19, 4, 189-202 (2012). doi:10.1002/kpm.1398

24. McDermott, R.: Measuring The Impacts Of Communities. How To Draw Meaning From Measures of Communities Of Practice. Knowledge Management Review, 5, 2, 26-29 (2002). retrieved from www.melcrum.com/e-library/

25. Lee, P. -S., Tseng, S.-M.: The Effects of Knowledge Management capability and Dynamic Capability on Organizational Performance. Journal of Enterprise Information Management, 27, 2, 158-179 (2014). doi:10.1108/JEIM-05-2012-0025

26. Yang, J-T.: The Impact Of Knowledge Sharing On organizational Learning And Effectiveness. Journal of Knowledge Management, 11, 2, 83-90 (2007). doi:10.1108/13673270710738933

27. Zack, M., McKeen, J., Singh, S.: Knowledge Management and Organizational Performance. Journal of Knowledge Management, 13, 6, 392-409 (2009). doi:10.1108/13673270710738933

28. Goldoni, V., Oliveira, M.: Knowledge Management Metrics in Software Development Companies in Brazil. Journal of Knowledge Management, 14, 2, 301-313 (2010). doi:10.1108/13673271011032427

29. McKellar, K., Pitzul, K, Yi,Y., Cole, D.: Evaluating Communities of Prsctice and Knowledge Networks: A Systematic Scoping Review of Evaluation Frameworks. EcoHealth, 11, 383-399 (2014). doi:10.1007/s10393-014-0958-3

30. Perrin, A.: The Practices of Knowledge Managers in Lafarge. Journal of Knowledge Management, 16, 2, 204-214 (2012). doi:10.1108/1367321211218825

31. Yahya, S. et Goh, W.K.: Managing Human Resources Towards Achieving Knowledge Management. Journal of Knowledge Management, 6, 5, 457-468 (2000). doi:10.1108/13673270210450414

32. Tashakkori, A. \& Teddie, C.: Mixed Methodology: Combining Qualitative and Quantitative Approaches. Sage, Thousand Oaks, CA. (1998) 